\title{
Do fragmento ao todo: sociedade e forma literária em Capão Pecado.
}

\author{
Alexandre Gomes Neves ${ }^{1}$
}

RESUMO: O presente artigo visa discutir questões que desafiam a crítica da literatura contemporânea, como a representação do espaço. Os espaços literários nos conduzem a uma experiência urbana marcada pela violência e pela segregação.

ABSTRACT: The present article discusses some questions that challenge the critical of contemporary literature, one of them being the space representation. The literary spaces lead us to an urban experience marked by violence and by segregation.

PALAVRAS-CHAVE: literatura contemporânea; literatura marginal; violência. KEYWORDS: contemporary literature; marginal literature; violence.

Capão Pecado 2 , de autoria de Ferréz, é um livro que nos incomoda profundamente. Incomoda nos temas que percorre e incomoda na forma. Uma forma disjuntiva, feita de muitos episódios violentos e perpassada por uma estória de folhetim de desfecho surpreendente, como deve ser um bom folhetim.

Uma série enorme de grandes temas sociais, muitos, específicos das periferias das grandes cidades figura no romance Capão Pecado. Acima de todos, como tema repetido a cada ruptura, encontra-se a violência endêmica bastante relacionada ao tráfico de drogas e de armas. Porém, encontramos outros como o alcoolismo e a forte presença do bar como um dos poucos lugares públicos de encontro e lazer; o desemprego; a crueldade de um espaço social que impossibilita a amizade, permitindo apenas alianças temporárias entre "manos" e

\footnotetext{
1 Mestrando na área de Estudos Comparados de Literaturas de Língua Portuguesa, FFLCH-USP. Pesquisa: Etnógrafos escritores: elementos para comparação das obras de Câmara Cascudo e Oscar Ribas.

2 FERRÉZ. Capão Pecado. $2^{\mathrm{a}}$. ed. São Paulo, Labortexto Editorial, , 2000.
} 
comparsas na contravenção; o embate entre a cultura negra e o avanço evangélico; a imagem da mulher, entre outros.

A forma fragmentada da narrativa abre para a reflexão de uma série de temas sociais vindos à tona em cada fragmento, a cada ruptura estabelecida no eixo da tríade amorosa. O que leva o leitor a perder-se entre as personagens e os muitos episódios, além de dificultar enormemente a apreciação crítica, já que a presença dos temas elencados acima, encaminha a obra para uma recepção que, freqüentemente, não ultrapassa os limites do documental. No entanto, é justamente a articulação de tais temas numa estrutura instável que garante o interesse do romance enquanto forma estética.

O eixo central da narrativa é a já batida tríade amorosa, aqui encenada por Rael, Matcherros e Paula, com direito a um quarto elemento. Rael, o protagonista, atendente de padaria e depois operário numa fábrica, apaixona-se por Paula, funcionária da fábrica na qual irá trabalhar. Problema: Paula é namorada de Matcherros, amigo de Rael. A forma do romance, no entanto, não permite ao leitor seguir tranqüilamente os enlaces e desenlaces amorosos. A fragmentação narrativa permite ao leitor acompanhar bem mais a representação do modo de vida que se pode ter na periferia de São Paulo, no bairro de Capão Redondo, onde se passa a história. O leitor acompanhará um cotidiano fragmentado e doloroso, onde toda e qualquer experiência com o espaço e com o outro é mediada pela violência.

Para comentar este romance foi escolhido como ponto chave a questão do espaço. Um elemento fundamental, já que o romance desde o título visa colocar um espaço determinado em cena, ou seja, o bairro Capão Redondo, um dos lugares conhecidos como dos mais violentos da cidade. 


\section{A questão do espaço}

A questão do espaço nas narrativas contemporâneas tem ganhado notoriedade. Tem-se constantemente verificado o fato de as narrativas serem predominantemente urbanas, o que vai ao encontro do rápido e intenso processo de urbanização do país. Dos anos 70 para cá a maior parte dos brasileiros passaram a viver em cidades. Acompanhando este processo, o espaço das narrativas brasileiras passou a ser muito mais o da cidade e, especificamente o espaço degradado da cidade na literatura dos anos 90.

Em "Sombras da cidade: o espaço da narrativa brasileira contemporânea"3, Regina Dalcastagné nos leva a refletir sobre o modo como o espaço urbano vem sendo representado em algumas obras contemporâneas. Para a autora haveria uma espécie de suspensão do espaço, que deixou de ser descrito na sua concretude e, sobretudo, deixou de ser vivido pelas personagens como possibilidade de elas constituírem uma experiência palpável. Como se houvesse uma incompatibilidade entre o sujeito e o espaço pelo qual circula, este oferecendo bem mais a visão de um absurdo inconciliável que leva ao isolamento do que a experiência do contato, seja com o espaço, seja com o outro.

Segundo Dalcastagné o espaço some entre a diversidade de ícones de uma sociedade de consumo. Recupera Renato Ortiz (Mundialização e cultura, 1996) para junto com ele dizer que diante dos avanços tecnológicos e do tipo de cultura que engendramos na atual fase do capital, os objetos produzidos e consumidos em larga escala constituem a nossa paisagem.

Numa parte do artigo a autora analisa personagens dos seguintes livros: Armadilha para Lamartine (1975) de Carlos e Carlos Sussekind, Uma noite em Curitiba (1995) de Cristovão Tezza e Um crime delicado (1997) de Sérgio Sant'Anna. Todos eles possuem como protagonistas,

3 DAlCASTAGNÉ, Regina. "Sombras da cidade: o espaço na narrativa brasileira contemporânea”. In Ipotesi, Juiz de Fora - v. 7 - n. 2 - jul/dez 2003. 
homens intelectualizados de classe média que se deslocam pela cidade a pé ou utilizando transporte público. No entanto, acompanhamos mais os discursos das personagens do que a presença da cidade, sendo que esta é construída pelo olhar das personagens a cada momento. Para a autora, a narrativa deixa vazios "que o leitor preenche com o repertório adquirido no contato com outras formas de representação - cinema, televisão, guias turísticos, etc” (Dalcastagné, 2003, p.16).

Ainda nas trilhas do mesmo artigo, outro dado fundamental do espaço urbano figurado através das letras seria a decadência e a segregação. Aí comparecem personagens da classe baixa, os que não possuem lugar na cidade e habitam albergues, cortiços, favelas, periferias ou as ruas mesmo. E ganham espaço os quadros da violência urbana, desde os assassinatos até as formas mais sutis de relação.

Assim temos de um lado o espaço suspenso, o espaço que não se adensa e não pode conferir às personagens nenhum tipo de experiência, e o deslocamento se dá como se tratasse de um lugar qualquer; de outro lado temos um espaço cuja experiência é a da privação. Quando vamos ler Capão Pecado, de antemão já sabemos com que tipo de experiência com o espaço vamos lidar, pois o signo Capão Redondo já está inscrito em nossas consciências através dos noticiários. O mesmo acontece quando nos deparamos com Estação Carandiru (1999) de Dráuzio Varela, outro exemplo de espaço social previamente demarcado tanto pelo autor quanto pelo leitor, antes mesmo de lermos já criamos uma expectativa que é a de um espaço degradado e segregado.

Num sentido que guarda alguma semelhança com Regina Dalcastagné, caminha o ensaio de Flora Sussekind, "Desterritorialização e forma literária: literatura brasileira contemporânea e experiência urbana" ${ }^{4}$. Neste ensaio, a autora analisa numa primeira parte, antes de incursões pela poesia, algo que para ela parece muito presente na atual narrativa que é a confluência entre

4 SUSSEKIND, Flora. "Desterritorialização e forma literária. Literatura brasileira contemporânea e experiência urbana”. In Literatura e Sociedade, São Paulo, n. 8, 2005. 
relato e fotografia, configurando o que autora denomina de "relatos ilustrados". Sussekind nos aponta para obras que se pautariam por um "espelhamento mútuo entre o fotográfico e o narrativo, entre a ilustração e as tramas testemunhais" (Sussekind, 2005, p.62).

Partindo da oposição entre processos de reterritorialização e processos de desterritorialização, Flora Sussekind nos oferece um interessante quadro para refletirmos sobre o espaço na literatura contemporânea. Reterritorializaçao seria o que vemos acontecer em romances como Capão Pecado (2000) de Ferréz ou Cidade de Deus (1997) de Paulo Lins. Por estes romances, perpassaria uma espécie de olhar etnográfico cujo objetivo é uma mera catalogação de imagens da violência. $\mathrm{O}$ processo da desterritorialização passa pelo encontro com o outro que provoca desestabilizações; passa ainda pela desfiguração dos corpos, pelas imagens do horror levadas às últimas conseqüências. Para a autora a desfiguração dos corpos e sua descrição nas narrativas representariam não só a crise, mas o reformular de novos corpos, novas identidades, outras subjetividades.

O que há de comum entre os dois posicionamentos críticos, afora a evidente urbanidade das narrativas, é a constatação da presença de um espaço que é eminentemente o espaço da segregação social, ou seja, as favelas, os presídios, as esquinas de prostituição, enfim o espaço segregado por onde partes da sociedade não podem circular. Espaços de tipos únicos, de pobreza homogênea.

Para Flora Sussekind, relatos ilustrados a exemplo de Capão Pecado perderiam o poder de crítica por apresentarem os espaços sociais segregados de modo estatizado. $\mathrm{O}$ teor documental desse tipo de obra nos levaria direto para o contexto extraliterário sem a devida mediação estética que caracteriza a forma literária. No entanto, é possivel pensar que as fotografias em Capão Pecado não representam mera ilustração que visa documentar um espaço segregado, elas possuem níveis distintos de leitura sendo imprescindíveis para a estrutura da obra. 
No título Capão Pecado e na capa do livro, já transparece o desejo do autor de representar um espaço que ficou à margem, excluído do processo de urbanização da cidade de São Paulo. Nas palavras do próprio Ferréz, em epígrafe posta entre o prefácio e primeira parte: "Querido sistema, você pode até não ler, / mas tudo bem, pelo menos viu a capa". O mesmo querido sistema não lendo poderá ainda folhear o livro e se deparar com outras imagens fotográficas a repercutir a imagem da capa, muito embora as fotografias do interior do livro indiquem mais que mero fotojornalismo ou relato ilustrado.

Capão Redondo é um espaço "fora das idéias" para utilizar a expressão de Ermínia Maricato em seu trabalho "As idéias fora do lugar e o lugar fora das idéias"5. Neste texto Maricato demonstra como surge uma enorme cidade ilegal, desconhecida, ignorada pelas instituições do Estado, incluindo os planos urbanísticos. Isto em nome da especulação fundiária e do tipo de investimento privilegiado no crescimento da cidade - viário/imobiliário. Observa a autora que como os baixos salários não incluem o custo da mercadoria habitação, os assalariados ficam obrigados a construções próprias, não planejadas e em locais irregulares. Sendo que a lei só é aplicada para locais valorizados, quando se trata de locais desvalorizados a ocupação é permitida. Assim surgem bairros inteiros da noite para o dia sem infra-estrutura, sem acesso aos bens que a cidade poderia oferecer e que são sonhados pelas levas de migrantes que continuam indo para as metrópoles em busca de recursos inexistentes em seus locais de origem.

Como aponta a autora, as conseqüências só poderiam ser: predação do ambiente, pois normalmente se ocupam locais de mananciais e de antigas reservas florestais e violência, pois o sonho da cidade não se concretiza abrindo portas para que toda uma juventude sem metas e sem destinos evolua dos pequenos roubos para as facções criminosas como podemos ver em Cidade de Deus, o filme. A cidade

\footnotetext{
${ }^{5}$ MARICATO, Ermínia. "As idéias fora do lugar e o lugar fora das idéias". In Arantes, Otília (org). A cidade do pensamento único: desmanchando consensos. Petrópolis: Vozes, 2000.
} 
ilegal, não incluída nos planos urbanísticos (daí a expressão "lugar fora das idéias”), permanece excluída, sem acesso aos bens da cidade, desde os mínimos como água encanada, luz elétrica, vias estruturadas, moradias dignas de habitação. A cidade ilegal só se torna verdadeiramente ilegal quando sua habitação atrapalha os planos de crescimento viário da cidade.

Este é o espaço de Capão Redondo representado em Capão Pecado. Embora não haja no livro longas descrições das moradias, dos becos e vielas do lugar, a menção ao espaço físico é sempre breve, o que nos faz pensar na pertinência dos ensaios críticos de Regina Dalcastagné e Flora Sussekind, podemos ter o sentimento do lugar através da apresentação do modo de vida das personagens. Neste caso não se trata de uma cidade mundializada, em que o espaço pode ser o de uma cidade qualquer com suas largas avenidas e viadutos e não o lugar onde se vive de modo específico; trata-se do espaço negado, em que a cidade é apenas sonhada ou odiada porque os personagens se encontram fora de suas margens. No caso de Capão Pecado um dos limites físicos é dado pela ponte da Av. João Dias, há dois lados da ponte, e em apenas um deles se encontra a cidade. Nesta obra podemos entender o espaço como personagem. O espaço da periferia urbana não é apenas o lugar onde homicídios terríveis acontecem, mas é o próprio lugar que acontece. Este espaço personificado insurge-se contra um outro espaço também personificado, o da cidade urbanizada. Neste sentido é que se assenta uma evidente perspectiva histórica: é exatamente o tipo de urbanização segregadora, historicamente consagrada pelas metrópoles brasileiras, que o romance representa de modo tão crítico quanto dramático.

Ainda que os blocos de fotografias do livro possam ser recepcionados pelos leitores dos dois lados da Ponte João Dias como ilustração que estaticamente reproduz a realidade vivida, penso que as fotografias possuem diferentes níveis de leitura e de significado. Num primeiro nível estaria a crítica à cidade urbanizada, o que numa perspectiva histórica demonstra o tipo de urbanização sofrida por São 
Paulo, cujos governantes sempre admitiram o surgimento da cidade ilegal. Este primeiro nível vai ao encontro do desejo do narrador e das vozes dos rappers que comparecem no romance. A sensação que os dois discursos nos passam, o verbal e não-verbal, é de vidas empilhadas, sem nenhum espaço para qualquer tipo de sociabilidade. Os personagens em Capão Pecado raramente marcam encontro, na maior parte das vezes eles se "trombam". Saem às ruas, vão a um bar, passam por uma viela, e aí estão todos, aglomerados, pilhados.

As imagens que não inspiram cartão postal, como está dito na legenda de uma das fotografias, dialogam de modo ostensivo com as imagens que todos nós vemos, e estamos mais acostumados a ver, como imagens da cidade de São Paulo com suas grandes avenidas, teatros, restaurantes e locais históricos. Poderíamos pensar, por exemplo, nas imagens que saltam de O fluxo silencioso das máquinas (2002) de Bruno Zeni. Neste, ao lado da crítica pontuada em alguns dos textos, não deixa de haver imagens que atestam num tom laudatório a grandiosidade positiva da cidade como metrópole catalisadora dos eventos do restante do globo. Poderíamos ainda pensar nas imagens de São Paulo registradas em eles eram muitos cavalos (2005) de Luiz Ruffato, para citar outro autor contemporâneo que também tematiza a violência e a degradação do espaço urbano. Em ambos, em diferentes graus de crítica, comparecem o trânsito da cidade, a violência em vários níveis, o consumismo, a luta entre as classes, a falta de sociabilidade, a perda dos sonhos e dos valores; de todo modo, tudo isto se dá no espaço da cidade legalizada. Muito embora seja um espaço que vive sua derrocada, trata-se do espaço que foi compreendido pelos investimentos públicos e privados.

A cidade de Capão Pecado é a outra, aquela que de modo algum pode ser retratada para um cartão postal, pois ela é o seu avesso. Não é a cidade dos automóveis em seu lento fluxo, mas a cidade dos becos por onde estes não transitam por falta de estrutura mínima. Assim as fotografias de Capão Pecado não apenas denunciam a vergonha das submoradias e da falta de lazer. Elas ainda se insurgem contra as 
imagens da São Paulo legal. As fotografias compõem junto com o texto a representação da radical segregação (espacial, econômica e racial) que há na cidade de São Paulo. Sendo assim, o espaço no romance só pode ser pensado tendo em vista o espaço que não está representado, ou seja, os lugares que serviriam para cartão postal da metrópole. A omissão do espaço legal é um dado estruturante da obra. O espaço das "quebradas" do Capão, normalmente negado como pertencente à cidade, é o único espaço presente na narrativa.

Num segundo nível de significado, as fotografias dialogam com o universo social e literário da contemporaneidade. Podemos verificar nas mais diversas obras um diálogo freqüente e diversificado com as artes visuais ${ }^{6}$. Tal diálogo talvez expresse a marca de um tempo em que as letras não ocupam e não poderão mais ocupar posição central na vida de qualquer sujeito, mesmo quando imerso no mundo das letras. A literatura concorre com as mais diversas mídias em que a palavra se cala. Interessante será notar a constante presença do videogame no romance, como única diversão capaz de unir as personagens, já que até o futebol de viela termina em agressões. Presença constante também da revista em quadrinhos que junto com edições de bolso adquiridas em sebos compõem o modo de Rael concretizar o seu direito à fantasia, através das letras e imagens.

O fato das letras terem perdido sua posição central, sobretudo na fabricação de imagens visuais talvez responda a constatação de Regina Dalcastagné de que nas narrativas contemporâneas há vazios imagéticos para o leitor preencher. Não creio que no caso de Capão Pecado as fotografias tenham mera função de preencher vazios, já que estes são reclamados na cidade legal mundializada, não creio que a função seja a de apresentar espaços que o verbo se vê incapacitado para cobrir, já que a estrutura do livro dá conta do espaço. E isto nos leva a um terceiro nível de significado para as fotografias.

\footnotetext{
${ }^{6}$ Há um diálogo com as artes visuais em obras como: O fluxo silencioso das maquinas (2002) de Bruno Zeni, eles eram muitos cavalos (2005) de Luiz Ruffato e Dárlin (2003) de Airton Paschoa, para citar algumas.
} 
Num terceiro nível de significado, podemos sugerir que o conteúdo das fotografias (casas empilhadas, ruas estreitas, córregos por onde escoam detritos, atravessados por pontes improvisadas por toras de madeira, crianças em carros abandonados) nos conduz para a própria estrutura da narrativa.

A narrativa em Capão Pecado é em forma de mosaico, vemos abrir muitas janelas a flagrar cenas do cotidiano, de violência naturalizada. Como se a narrativa fosse composta por episódios empilhados.

Na pizzaria, cerveja era água. Ratinho, Jacaré e Ceará haviam assaltado uma loja de conveniência em Moema e estavam bancando tudo. Geóvas, Pássaro, Zé do Carmo, Kim, Jura e outros manos tavam só na serra, a noite estava garantida.

Na boca, China comprava umas buchas para ela fumar com Ratinho, Nana e Mixaria.

Marquinhos havia acabado de chegar, tinha vendido quase toda a carga de algodão e apesar de estar a fim de beber umas cervejas geladas, não iria a pizzaria por causa de sua mina, que o esperava em casa para uma longa noitada de amor. (Ferréz, 2000, c. 12, p.108)

A abertura de quadros fotográficos de maior ou menor extensão que caminham ao lado da trama amorosa são comuns no universo deste romance. Alguns quadros são longos como a história de Capachão, garoto abandonado pelos pais e pela avó que se tornará policial, ou a longa história do alcoólatra Carimbê a ocupar todo o capítulo 15. A sensação é a de que as peças do mosaico estão meio soltas podendo a qualquer momento se desgrudar, assim como as casas empilhadas, os carros velhos, a toras sobre os córregos nas fotografias. Trata-se de todo um universo provisório que pode se desmanchar a qualquer momento. E, no entanto se mantém. Os espaços não planejados e em ruínas presentes nas imagens visuais se ajustam perfeitamente a própria construção da narrativa. Há uma solidariedade estrutural entre o conteúdo desarmônico e fragmentário das fotos e a seqüência episódica e desarmônica da narrativa. Assim como nas fotografias são retratados muitos anônimos, também entre as 
personagens encontramos muitos seres irrelevantes para a trama romanesca e para o percurso do protagonista; constituem "apenas mais um” e seu pequeno retrato só ganha significado no conjunto. Um conjunto de vidas pilhadas, nos dois sentidos que pilhadas pode possuir, vidas postas umas sobre as outras de modo qualquer; vidas roubadas, subtraídas.

\section{Referências bibliográficas}

DALCASTAGNÉ, Regina. "Sombras da cidade: o espaço na narrativa brasileira contemporânea”. In Ipotesi, Juiz de Fora - v. 7 - n. 2 - jul/dez 2003.

FERRÉZ. Capão Pecado. 2a ${ }^{\text {a }}$ ed. São Paulo, Labortexto Editorial, , 2000.

MARICATO, Ermínia. "As idéias fora do lugar e o lugar fora das idéias". In Arantes, Otília (org). A cidade do pensamento único: desmanchando consensos. Petrópolis: Vozes, 2000.

ORTIZ, Renato. Mundialização e cultura. $2^{\text {a }}$. ed. São Paulo: Brasiliense, 1996.

PASCHOA, Airton. Dárlin. São Paulo: Nankin Editorial, 2003.

RUFFATO, Luiz. eles eram muitos cavalos. $3^{\text {a }}$. ed. São Paulo: Boitempo Editorial, 2005.

SUSSEKIND, Flora. "Desterritorialização e forma literária. Literatura brasileira contemporânea e experiência urbana”. In Literatura e Sociedade, São Paulo, n. 8, 2005.

ZENI, Bruno. O fluxo silencioso das máquinas. São Paulo: Ateliê Editorial, 2002. 